\title{
ORGANIZATIONAL CULTURE AND KNOWLEDGE TRANSFER IN PROJECT- BASED ORGANIZATIONS: THEORETICAL INSIGHTS FROM A CHINESE CONSTRUCTION FIRM
}

\begin{abstract}
We conducted an empirical, fine-grained investigation of the impact that three main elements of organizational culture - artifacts, norms, and shared beliefs - have on the transfer of knowledge across projects in a project-based organization. Within a single case study research design, we collected and analyzed rich and detailed information from documentation, archival data, and in-depth semistructured interviews with very experienced project managers of a Chinese construction firm. Our findings advance extant research on professional cultures and subcultures by showing how cultural elements at the corporate level interplay with the culture of lower organizational levels to influence individual choices on (1) which types of knowledge are most important to transfer, and (2) the extent to which it is acceptable to share or hoard knowledge. Our study also contributes to the literature on the legitimacy of knowledge by showing how organizational culture influences people’s perceptions of "knowledge authority” and shapes their preferences for specific knowledge transfer mechanisms.
\end{abstract}

Key words: knowledge management; knowledge transfer; organizational culture; projectbased organizations 


\section{INTRODUCTION}

The project-based organization (PBO) is an organizational form whereby projects are the primary units for coordinating and integrating production and innovation (Hobday, 2000; Lundin \& Söderholm, 1995). By leveraging the temporary and unique character of projects, PBOs align and realign their structures, capabilities and strategies to foster innovation (Keegan \& Turner, 2002) and fulfil the needs of new customers and markets (DeFillippi \& Arthur, 1998; Gann \& Salter, 2000; Hobday, 2000). Over the past decade, scholars have increasingly sought to understand how PBOs achieve sustained competitive advantage, and what theoretical implications this may have for strategic management research in general (Cattani, Täube, Ferriani, Frederiksen, \& Silverman, 2011; DeFillippi \& Arthur, 1998; Whitley, 2006). In particular, increasing attention has been paid to the PBO’s ability to leverage learning and reusing knowledge across projects (Pemsel \& Müller, 2012; Pemsel \& Wiewiora, 2013; Sense, 2004, 2007). In a knowledge-based perspective, organizational knowledge is the firm's main strategic resource and the basis for competitive success (Grant, 1996; Kogut \& Zander, 1992; Spender, 1996; Spender \& Grant, 1996; Zander \& Kogut, 1995). The ability to create, manage, and leverage knowledge assets systematically can contribute substantially to the achievement of long-term goals (De Long \& Fahey, 2000), and firms that are particularly successful at transferring and reusing knowledge internally are more likely to attain sustained competitive advantage (Argote \& Ingram, 2000). But although the benefits of knowledge transfer in projectbased settings have long been recognized (Ajmal \& Koskinen, 2008; Pemsel \& Wiewiora, 2013), the effective reutilization of knowledge within and across projects still faces challenges and difficulties in practice (Bartsch, Ebers, \& Maurer, 2013).

Many scholars agree that one of the biggest challenges to knowledge transfer in projects is posed by the organization's culture (Ajmal \& Koskinen, 2008; Wiewiora, Trigunarsyah, Murphy, \& Coffey, 2013). We know that organizational culture influences project teams' 
decisions on whether to share and exchange project-related knowledge (Ajmal \& Koskinen, 2008), and it often limits the transfer of lessons learned and the emulation of innovative approaches (Eskerod \& Skriver, 2007). However, a specific and complete understanding of how such influence takes place is still missing, and we do not know what role each of the fundamental elements of an organization's culture play in the process. To start tackling this research problem, we asked the following question: How do the different elements of organizational culture influence the transfer of knowledge in PBOs?

We adopted a single case study research design to investigate the knowledge transfer activities carried out by a large Chinese PBO. To triangulate extensive and detailed information from multiple sources and fully exploit the richness and depth of the case study design (Yin, 2013), we collected and analyzed data in the form of interviews, documents, and archives. Data collection and analysis proceeded concomitant and intertwined through several rounds of constant comparison of the collected data and theoretical sampling of new data (Corbin \& Strauss, 2014; Glaser \& Strauss, 1967). This enabled us to tease out and study separately three main elements of organizational culture: artifacts, norms and shared beliefs. We found that each of these elements exerts a strong influence on a number of aspects of the transfer of knowledge across projects, but that such influence is multifaceted and often contradictory.

Our findings extend early work on professional cultures (Ajmal, Kekale, \& Koskinen, 2009; Ajmal \& Koskinen, 2008) and subcultures (De Long \& Fahey, 2000) by identifying a subtle interplay between corporate-level organizational culture and cultural elements at lower organizational levels. In the experience of our case-study firm, such interplay determines not only (1) which types of knowledge are most important to share, transfer and leverage, but also (2) the extent to which knowledge can be shared or hoarded, and (3) the specific circumstances in which sharing or hoarding should occur. Although knowledge hoarding issues have often been identified in project environments (Evans, Hendron, \& Oldroyd, 2015; Hall \& Sapsed, 
2005; Issa \& Haddad, 2008), we have found that organizational culture may confer on experienced mentors within projects a unique position of authority that enables them to select the knowledge that is leveraged and shared, and adopt widely accepted and tolerated knowledge-hoarding behaviors. Finally, our study advances extant research on the legitimacy of knowledge (De Long \& Fahey, 2000; Heusinkveld, 2009; Hudson \& Wong-MingJi, 2001) by suggesting that national and organizational cultures may give a legitimate identity to knowledge that is closely tied to the formal authority of the firm, and influence people's preference as to which formal or informal knowledge transfer mechanisms are to be enacted.

\section{THEORETICAL BACKGROUND}

Knowledge is a crucial resource of organizations, and its systematic transfer and reutilization underpins higher performance and sustained competitive advantage (Argote, 1999; Spender, 1996; Spender \& Grant, 1996; Zander \& Kogut, 1995). In project-based settings, the transfer of organizational knowledge across projects provides the opportunity to exploit and leverage valuable lessons learned, avoid the repetition of mistakes (Almeida \& Soares, 2014), and improve overall project performance (Landaeta, 2008). In their seminal work, Argote and Ingram (2000) define knowledge transfer as the process through which the performance of one unit - a group, department, or division - is affected by the experience of another. In particular, the authors use the term "knowledge reservoirs" to connote that knowledge can be stored for future use. For example, it can be embedded in individual members of the organization, in its tools, technologies, and tasks, as well as the networks formed by variable combinations of such members, tools, technologies, and tasks. Therefore, knowledge can be transferred by moving such reservoirs and networks, as it occurs when individuals are reallocated across units, or when technologies and routines developed in an organization are adopted by another. 
Alternatively, the transfer can be performed by modifying the knowledge reservoirs and networks at the recipient unit, especially through initiatives of internal communication and training (Argote, 2012; Argote \& Ingram, 2000; Argote, McEvily, \& Reagans, 2003; Argote \& Miron-Spektor, 2011).

Typically, the transfer of knowledge presents difficulties and challenges (Kane, Argote, \& Levine, 2005), because the knowledge reservoirs and networks comprise complex interactions that cannot be easily reproduced at the recipient context (Argote \& Ingram, 2000). Similarly, both individual- and group-level characteristics, such as motivations or absorptive capacity, may affect the transfer performed via internal communication and training initiatives (Argote \& Ingram, 2000). In PBOs, the spatial and temporal setting in which projects are executed constitutes the context for the transfer (Kamara, Anumba, \& Carrillo, 2008), and the fact that projects may be carried out in parallel or in sequence determines whether and when the transfer occurs. Knowledge can be transferred across projects that run in parallel via job rotation and mentoring, without the intervention of organization-level transfer mechanisms; whereas the transfer between projects that are delivered in sequence is usually mediated by knowledge bases and structures maintained at the firm level (Kamara et al., 2008). In either case, various hindrances to the transfer often arise from the transient nature of projects and from the fact that the primary focus of project teams is usually on time, cost, and quality, rather than on sharing lessons learned (Pemsel \& Wiewiora, 2013). In fact, the completion of the project usually puts an end to collective learning (Pemsel \& Wiewiora, 2013), and it is often unlikely that project staff evaluate their project experiences systematically, and document the new ideas and insights from which other projects may benefit (Ajmal \& Koskinen, 2008). Also, since projects have a high degree of autonomy and independence, the integration and coordination of knowledge transfer capabilities across project boundaries is very difficult (Pemsel \& Wiewiora, 2013). 
After completion, project teams will rather be reorganized and allocated to new assignments, and individuals will have limited time for sharing what they learned (Brady \& Davies, 2004).

Notwithstanding the many obstacles posed by the transiency of project endeavors, organizational culture is widely regarded as the most important enabler of, and impediment to, the management and transfer of organizational knowledge (Ajmal \& Koskinen, 2008; Allen, 1984; Davenport, Jarvenpaa, \& Beers, 1996; Leidner \& Kayworth, 2006; McDermott \& O’Dell, 2001; Tushman, 1977). Although information and communication technologies have expanded the opportunities for storing, reusing and leveraging knowledge, people remain both essential actors and ultimate beneficiaries of the transfer process (Aubrey \& Cohen, 1995; Fiol \& Lyles, 1985; Kamara et al., 2008; Szulanski, 1996). Knowledge-related activities require social interaction and human cognition (Ajmal \& Koskinen, 2008; Hsu \& Sabherwal, 2012; Lee, Gon Kim, \& Kim, 2012; McDermott, 1999) and are shaped and influenced by cultural factors. In particular, organizational culture determines the underlying assumptions upon which knowledge is managed and shared, mediates the interplay between the individual and the organizational level, and suggests who is expected to control and share the transferred knowledge (De Long \& Fahey, 2000; Janz \& Prasarnphanich, 2003; Karlsen \& Gottschalk, 2004; Rai, 2011; Simonin, 2004; Wang, Su, \& Yang, 2011). The cultural traits of the organization set the context for social interaction, inform the process by which new organizational knowledge is created, legitimated and distributed (Alvesson \& Kärreman, 2001; De Long \& Fahey, 2000; Karlsen \& Gottschalk, 2004; Zheng, Yang, \& McLean, 2010), and exert positive or negative influence upon its transfer (Ajmal \& Koskinen, 2008).

Organizational culture is a multifaceted concept (Barney, 1986; Cameron \& Quinn, 2005; Handy, 2007; Hofstede, Neuijen, Ohayv, \& Sanders, 1990; Schein, 1990). Schein (2010) defines it as "a pattern of shared basic assumptions learned by a group as it solved its problems of external adaptation and internal integration, which has worked well enough to be considered 
valid and, therefore, to be taught to new members as the correct way to perceive, think and feel in relation to those problems” (Schein, 2010: p. 18). Based on Schein’s work, Cummings and Worley (2014) create a composite model of organizational culture comprising four major elements: artifacts, norms, espoused values and beliefs, and basic underlying assumptions.

Artifacts are at the surface of organizational culture. They are perceived as the visible symbols of other, deeper cultural elements (Schein, 2010), and include any visible products of the organization: physical layouts and their style, rules and procedures, and the observable behavior of people, such as dress code, language and emotional displays (Schein, 2010). Norms are at the second level of organizational culture. These are unwritten rules that guide people's behavior in specific situations (Cummings \& Worley, 2014). The next, deeper level is represented by values and beliefs, which include ideals, goals, aspirations and ideologies (Schein, 2010) that inform people about what is important and deserves attention in the organization's life (Cummings \& Worley, 2014). Values and beliefs may or may not be congruent with behavior and artifacts. Some espoused values and beliefs are congruent with the basic underlying assumptions that guide people’s performance (Wilkins \& Ouchi, 1983), some are only part of the ideology or philosophy of the organization, and some others only support the organization's aspirations for the future (Schein, 2010). As shared values and beliefs are abstract and might be mutually contradictory, understanding the basic underlying assumptions can help decipher culture and predict people's behavior more accurately. Basic assumptions are at the deepest level of organizational culture, and can be conceived of as unconscious, taken-for-granted suppositions on how issues should be tackled. Because of their fundamental role in underpinning people’s behavior, perceptions, and feelings in any situation, basic underlying assumptions are non-confrontable and non-debatable, and they are extremely difficult to track and change (Schein, 2010; Stokes, Baker, \& Lichy, 2016). 
We know that, overall, organizational culture guides people's thoughts and choices, and provides terms of reference for what is right and wrong doing about project-related knowledge and learning (Ajmal \& Koskinen, 2008). Eskerod and Skriver (2007) found that some basic assumptions of project managers (e.g., masculine values, perception of time, focus on present and very near future, relationships with peers, sense of ownership of the projects, and conception of the project manager role) limit the transfer of lessons learned and the emulation of innovative approaches across projects. However, empirical evidence is often contradictory, and our understanding of the different role that each of the main elements of organizational culture plays in the transfer and reutilization of knowledge in project-based settings is still limited. For example, Wiewiora et al. (2013) found that in some PBOs project managers were willing to share all types of lessons learned, including new knowledge about mistakes and pitfalls, and even tended to regard pitfalls as fundamental opportunities for further improvement. But in other PBOs, the authors found evidence of knowledge-hoarding behaviors, in that project managers who were particularly protective of their own knowledge used it selectively, and only shared it when this helped sustain their reputation and prestige in the organization for the purpose of career development and internal competition (Wiewiora et al., 2013).

To puzzle out such contradictions and achieve a deeper understanding of the interrelationships between organizational culture and knowledge transfer it is important to take into account that cultural dynamics in PBOs are extremely complex and sophisticated due to the interplay between the organizational macro environment and various layers of subcultures (Sackmann, 1992; Schein, 2010). Subcultures are subsets of the organization's overall culture that reflect the occupational identities of groups and contribute to define and orientate their unique experiences (Alvesson, 2012; Schein, 2010). Indeed, the multidisciplinary nature of projects implies close collaboration between professionals from diverse backgrounds, and with 
different professional cultures and approaches, which are not always aligned with the prevailing culture of the project (Ajmal \& Koskinen, 2008). As a result, project managers are often faced with the challenge of dealing with different cultures simultaneously, including the subcultures of various departments within the organization, and the core cultures of external organizations (Ajmal \& Koskinen, 2008). At the same time, macro-level cultural dimensions such as the national culture (Rivera - Vazquez, Ortiz - Fournier, \& Flores, 2009) exert a powerful influence upon the feelings and thoughts of project teams (Ray, 2014), and contribute to shape their basic underlying assumptions (Hofstede, 2010; Schein, 2010).

Given the complexity of cultural problems in project settings and the contradictory evidence emerging from extant empirical research, it is fundamental to take a closer look at the role that each component of organizational culture plays. Therefore, we asked the following research questions: How do the different elements of organizational culture influence the transfer of knowledge in PBOs?

\section{METHODS}

To address the above question, we employed a single case study research design. In-depth case studies enable researchers to collect rich information from multiple, complementary sources, including interviews, documents, physical artifacts, and direct observations (Yin, 2013). Wiewiora et al. (2013) argue that the case study approach is appropriate to examine issues of organizational culture and knowledge management, because the triangulation of multiple data sources provides powerful insights into complex and ambiguous phenomena. In fact, such research design is widely used to gain a deep understanding of research problems and generate new theoretical insights (Yin, 2013). A large Chinese state-owned firm of the construction industry - which we call Builc to ensure anonymity - was chosen for the fieldwork. Although 
issues of organizational culture can be studied in many different organizations around the globe (Schein, 2010), we opted for this empirical setting because it provided specific guarantees of theoretical relevance. In particular, as suggested by a growing body of research (Ralston, Terpstra-Tong, Terpstra, Wang, \& Egri, 2006; Shao, Feng, \& Liu, 2012), we expected to find and appreciate in this organization important aspects of the national culture as part of the overall system of interrelationships between organizational culture and the management and transfer of knowledge across projects (Alvesson, 2012). Builc is a large project-based organization whose main business scope includes construction and engineering projects carried out by employing a vast endowment of human and technical assets. As a corporation, the firm allocates construction projects to 15 general construction companies, and organizes a vast flow of people and resources both across the general construction companies and between these and the parent company as a whole. This setting provided us with extraordinary opportunities for studying the influence of organizational culture on knowledge transfer across projects.

\section{Data Collection}

In preparation for the fieldwork, we collected publicly available information about the firm and carried out conversations with colleagues and experts of the construction industry to learn more about the empirical setting, and prepare the interaction with our informants (Collins, 2004; Collins \& Evans, 2008). We used a combination of 157 between documents and archives and 20 semistructured interviews as our main sources of data. We selected the first informants based not only on their position in the firm, but also on their knowledge, expertise, and ability to provide insightful information about the research problem. With the help of the first interviewees, we followed a snowball approach (Biernacki \& Waldorf, 1981) to identify and interview new informants until the data collected and analyzed provided no new insights (Glaser \& Strauss, 1967). We purposefully selected (Lincoln \& Guba, 1985) very experienced 
project managers because these professionals played an important role in integrating and connecting multiple sources and flows of knowledge both within and across projects. Indeed, our informants participated directly in knowledge management and transfer processes, and interacted very actively with colleagues from other projects. To solve discrepancies of job titles between the Chinese and the western systems, the job title of “project manager” was readapted to capture more precisely the information about specific roles. In particular, we distinguished between Project Managers (7 informants), Senior Project Managers (8 informants), and Project Directors (2 informants). All interviewees had managerial and leadership roles in projects that were being delivered at the time of data collection. They were very competent and experienced professionals (for example, 13 of them possessed professional qualifications as chartered engineer and certified constructor), and deeply knowledgeable about Builc’s organizational culture (6 of them had worked at Builc for more than 20 years, and the total experience of all informants exceeded 235 years). Table 1 reports the details of our interviewees and their professional profile.

We adopted an interview protocol to ensure consistency of the data collection process and provide guidance during the interviews. The protocol was first designed and tested in English, and then translated into Chinese. The Chinese version was edited and revised carefully to mirror the conceptual framework underlying the English version. Before starting the actual data collection, we carried out three pilot interviews to tailor the interview questions to the specificities of the organization and the groups of informants. We used semistructured interviews because this interview format provided the necessary level of control over the interview process: it enabled us to ask open-ended questions, and then continue with followup questions when we needed to elicit further details on specific aspects of the research problem. Interviews were recorded and lasted between 45 and 90 minutes. At the beginning of each interview we asked broad or generic questions and engaged in active listening to build rapport 
with the interviewee (Given, 2008). Given our interest in cultural issues, the very first phase of the interview was crucial in setting the stage for discussing sensitive information and drawing out insightful reflections.

Table 1. Details of interviewees and their professional profile

\begin{tabular}{|l|c|c|c|c|c|c|}
\hline \multirow{2}{*}{ Interviewees } & \multirow{2}{*}{ Code } & \multicolumn{2}{|l|}{ Professional Qualifications } & \multicolumn{3}{|c|}{ Years at Builc } \\
\hline & & $\begin{array}{c}\text { Chartered } \\
\text { Engineer }\end{array}$ & $\begin{array}{c}\text { Certified } \\
\text { Constructor }\end{array}$ & $\leq 10$ & $\mathbf{1 1 - 2 0}$ & $\geq 20$ \\
\hline Project Director 1 & PD1 & & & & $\bullet$ & \\
\hline Project Director 2 & PD1 & & & & $\bullet$ & \\
\hline Project Manager 1 & PM1 & & $\checkmark$ & $\bullet$ & & \\
\hline Project Manager 2 & PM2 & & $\checkmark$ & & $\bullet$ & \\
\hline Project Manager 3 & PM3 & & & & & $\bullet$ \\
\hline Project Manager 4 & PM4 & & & $\bullet$ & & \\
\hline Project Manager 5 & PM5 & & & $\bullet$ & & \\
\hline Project Manager 6 & PM6 & & & $\bullet$ & & \\
\hline Project Manager 7 & PM7 & $\checkmark$ & & & $\bullet$ & \\
\hline Senior Project Manager 1 & SM1 & $\checkmark$ & $\checkmark$ & & & $\bullet$ \\
\hline Senior Project Manager 2 & SM2 & $\checkmark$ & & & & $\bullet$ \\
\hline Senior Project Manager 3 & SM3 & & & & & $\bullet$ \\
\hline Senior Project Manager 4 & SM4 & $\checkmark$ & & & $\bullet$ & \\
\hline Senior Project Manager 5 & SM5 & & $\checkmark$ & & & $\bullet$ \\
\hline Senior Project Manager 6 & SM6 & $\checkmark$ & $\checkmark$ & & & $\bullet$ \\
\hline Senior Project Manager 7 & SM7 & $\checkmark$ & & & & $\bullet$ \\
\hline Senior Project Manager 8 & SM8 & $\checkmark$ & $\checkmark$ & & $\bullet$ & \\
\hline Total & $\mathbf{1 7}$ & $\mathbf{7}$ & $\mathbf{6}$ & $\mathbf{4}$ & $\mathbf{6}$ & $\mathbf{7}$ \\
\hline
\end{tabular}

The subsequent questions aimed to explore the perceptions and opinions of respondents on more complex issues of interplay between specific elements of the organizational culture and the knowledge management and transfer practices. The final set of questions enabled us to probe for more information and clarification of the previous answers (Barriball \& While, 1994). Overall, all questions were phrased in accordance with methodological indications to minimize 
bias (Fraser, Greene, \& Mole, 2007). We followed theoretical guidance from existing research in focusing on practices of knowledge transfer broadly intended, including knowledge receiving, reusing and sharing, and the mechanisms through which knowledge is transferred. For example, some of the questions aimed to tease out the informant's perception on whether managing, sharing, and transferring knowledge was important/desirable/appropriate or not. Based on the first answers, follow-up questions probed into the role of artifacts, norms and shared beliefs and their impact on knowledge transfer.

In combination with the interviews, we used documents and archives as additional source of primary data for triangulation purposes (Yin, 2013). These included, for example, the firm's policies and procedures of project and corporate governance, documents reporting rules for punishing/rewarding project managers, statements of the "company profile”, “corporate culture”, “corporate leadership”, and “development vision”. Further documental and archival data were provided by internal case studies, papers, policy statements and reports about activities and topics as diverse as "employee training”, the "entrepreneurial attitudes of employees", the “development of human resources”, "rewards for innovative ideas", “promoting quality”, and "rewarding outstanding construction project managers”. Apart from constituting an important source of primary data relevant to the impact of organizational culture on knowledge management and transfer, this material also helped us isolate key themes for further analysis of the interview data. Table 2 contains a detailed list of the documents and archives.

\section{Data Analysis}

Interviews were first transcribed in Chinese and then translated into English. The English version of the transcripts was used to analyze the data and extract examples of data incidents in support of our findings. The analytical process followed Miles and Huberman's (1994) 
indications for data display, reduction, and verification. These techniques are widely used by

authors in project management studies (e.g. Pemsel \& Wiewiora, 2013).

Table 2. Details of documents and archival data

\begin{tabular}{|c|c|c|}
\hline Document Subject/Title & Type & Items \\
\hline Company Profile and Mission & Statement & 1 \\
\hline Corporate Culture & Statement & 1 \\
\hline Corporate Leadership & Statement & 1 \\
\hline "Build remarkable skills" - Best-practice-enhancing activity & Report & 1 \\
\hline "Dare to stand at the forefront" - Best-practice-enhancing activity & Report & 1 \\
\hline "My best work" - & Report & 1 \\
\hline "So that each project is fine" - Best-practice-enhancing activity & Report & 1 \\
\hline "Trying to learn honesty" - & Report & 1 \\
\hline "Whatever" Has Become a Habit - Best-practice-enhancing activity & Report & 1 \\
\hline Awards ceremony report & Report & 6 \\
\hline Construction Young Volunteers in Action & Report & 1 \\
\hline Group meeting report & Report & 17 \\
\hline Knowledge contest - & Report & 19 \\
\hline National construction enterprise leader summit & Report & 1 \\
\hline National Workers Microblogging Contest & Report & 1 \\
\hline New learning platform for training & Report & 1 \\
\hline New staff new experience: I am proud to be a construction worker & Report & 1 \\
\hline Outstanding construction project manager award & Report & 3 \\
\hline Pragmatic and Honest People - Best-practice-enhancing activity & Report & 1 \\
\hline Province outstanding entrepreneurs & Report & 1 \\
\hline Quarterly Comprehensive Inspection of Project Management & Report & 23 \\
\hline Site safety and quality standardization demonstration & Report & 1 \\
\hline Team spirit boosting - & Report & 7 \\
\hline Training Notes & Report & 27 \\
\hline Training practice meeting & Report & 2 \\
\hline Voluntary service activities & Report & 4 \\
\hline Youth Fellowship & Report & 1 \\
\hline Youth recreational activities & Report & 5 \\
\hline Construction Workers Leave System & Policy & 1 \\
\hline Corporate Governance & Policy & 1 \\
\hline General contracting & Policy & 1 \\
\hline Project Governance & Policy & 1 \\
\hline Rules for Punishing and Rewarding Project Managers & Policy & 1 \\
\hline "Young face covered with sweat" & Paper & 1 \\
\hline Build a leadership style in construction & Paper & 1 \\
\hline Construction workers to improve the work style & Paper & 1 \\
\hline Implement improvements to win the trust of workers & Paper & 1 \\
\hline Construction Engineering Machines and Facilities Learning & Case-study & 9 \\
\hline Group learning model & Case-study & 1 \\
\hline In-depth project supervision study & Case-study & 5 \\
\hline Site in-depth research project & Case-study & 1 \\
\hline \multirow[t]{2}{*}{ Banner "The Power of Example" } & Banner & 1 \\
\hline & Total & 157 \\
\hline
\end{tabular}


Data analysis started with three rounds of open coding of interview and document data. We assigned codes in the form of tags to identify units of meaning, and retrieve and organize data incidents, constructs and themes (Miles \& Huberman, 1994). After this first-level coding, the codes were grouped into emerging patterns and higher-order themes (Miles \& Huberman, 1994). The pattern codes were used to group the summaries of data incidents (first-level codes) into a smaller number of sets, themes and constructs (Miles \& Huberman, 1994). Then, pattern codes were grouped into higher-level categories. Following the analytic technique of patternmatching, we identified similarities and differences between data incidents and groups of codes (Eisenhardt, 1989; Yin, 2013). In addition, we used explanation-building techniques to understand how various elements of organizational culture exerted influence upon the transfer of knowledge across projects. Pattern-matching and explanation-building enabled us to search for patterns and themes, make contrasts and comparisons, and verify them against both existing and newly emerging findings. Through the combined use of pattern-matching, explanationbuilding, and reiterated coding and re-coding across levels of data aggregation, we ensured and maintained internal validity throughout the research process.

\section{FINDINGS}

The systematic management and transfer of knowledge made a significant contribution to project performance at Builc, and helped the firm expand and leverage its knowledge reservoirs. Project managers stated clearly that, when knowledge was reused effectively, many projectrelated problems and pitfalls could be avoided, and this led to reducing reworks, costs, and waste. The firm encouraged the cross-project exchange of ideas and innovations in construction techniques and methods in order to meet the varying requirements of future projects. New construction techniques/methods and innovative project management approaches represented 
the most important types of knowledge transferred and reused from project to project. Similarly, knowledge related to safety and quality control and management was transferred and reused frequently. Senior managers consistently stressed the importance of safety and quality, as both had great impact on the reputation of the firm and its ability to attract new clients.

We found that different elements of Builc's organizational culture played a different role in influencing whether, how, and to what extent knowledge transfer was pursued and implemented. Specifically, we collected empirical evidence of strong influences exerted by three types of cultural elements: artifacts, norms, and shared beliefs.

Artifacts are visible products of human activities in organizations, both tangible and intangible ones, including formal knowledge transfer mechanisms. All our sources of data documents, archives, and interviews - provided rich information about a wide range of artifacts used to transfer knowledge, such as learning materials, operational procedures, and routines for job rotation and quality inspection and control. This category of artifacts played a key role in encouraging and enhancing knowledge transfer practices as a continuing endeavor. For example, we learned that "the firm organizes regularly site visits, quarterly inspections, seminars and presentations” to support the exchange of ideas and experiences. As a project director explained, "when we finish a project, we have the post-project review, where we evaluate best practices and lessons learned. Moreover, the firm organizes training sessions, monthly and half-yearly meetings, site visits, and we also have monthly newsletters.” An artifact that was becoming increasingly important at Builc at the time of our study was the Enterprise Information Platform, an online information storage and sharing system where project-related best practices and insights could be uploaded for sharing purposes. Some of the evidence emerging from our analysis, however, shows a bivalent or at least ambiguous role of artifacts in relationship to the effectiveness of knowledge transfer. Some artifacts that had been conceived of to encourage the sharing and reutilization of knowledge, actually inhibited or 
hindered the transfer process. When asked for evidence of this type of artifacts, informants referred, for example, to quarterly inspections: "quarterly inspections come with punishments and rewards, and project managers responsible for projects where the performance of safety and quality control and management do not reach the desired standards will be punished and fined.”

Norms were the second element of organizational culture that we investigated. The most important and relevant norm that pervaded the working ethos of Builc's employees at all levels of the project hierarchy was one that affirmed the crucial importance of mentoring and apprenticeship in the day-to-day experience of project teams. In close application of such norm, mentoring and apprenticeship were widely used to build and strengthen competences and expertise across the firm, which still relied heavily on the handwork of project teams and the experience that mentors had acquired in past projects. In the words of a project director and a senior project manager, "traditionally, learning and knowledge sharing in the [Chinese] construction industry rely on mentoring and apprenticeship. Since the fundamental knowledge in textbook lacks practical relevance, you should acquire knowledge from experienced mentors"; thus, "for all construction workers and project actors, mentoring is the main way to learn new knowledge.”

Shared beliefs were the third element of organizational culture that we investigated. Although project managers reported that project teams were willing to receive, reuse and share knowledge for several reasons, other pieces of evidence suggested that some shared beliefs prompted project staff to be selective in their knowledge transfer initiatives. For example, there was the shared belief at the corporate level that safety and quality were top priority of any knowledge management initiative, because all project pitfalls potentially undermining the structural features of buildings or the health and safety of construction workers had to be prevented. Also, project managers firmly believed that no members of staff should allow 
themselves to make the same mistake twice, although it was widely accepted that the occurrence of new/unknown pitfalls could not be avoided completely. The same beliefs about the importance of sharing accurately the lessons learned about safety and quality issues were expressed by employees in all job positions. This reflected the widespread conviction that "any aspects of safety control and management cannot be ignored” and any knowledge, information or clues about them must be shared, communicated, and discussed as much as possible. These concepts were expressed in statements like:

The occurrence of project pitfalls cannot be totally avoided but we should keep it to a minimum. For the organization as a whole, the senior management highlights that safety and quality are top priority. SPM1

We must prevent pitfalls posing threats to the structure of buildings or the health of our people. PM7

Similar mistakes cannot be made in future projects. They cannot be made twice. SPM8

We have the awareness that any project mistake cannot be made twice. SPM7

Therefore, project managers believed that circulating new lessons learned as much as possible was fundamental. Such belief went hand in hand with another shared belief: that, due to numerous technical challenges encountered during the delivery of the projects and the heavy workloads associated with each project assignments, the limits of individual knowledge reservoirs could only be overcome by practicing and contributing to mutual learning as much as possible.

Due to the increasing complexity and workloads on projects, my colleagues exchange a lot of knowledge... We learn from each other... Everyone's experience in executing projects is limited. Receiving knowledge and learning from others is important. PM7

The accumulation of knowledge is facilitated through learning. The reuse of knowledge contributes to the improvement of our knowledge repositories. PM6

They [project managers] understand that their personal knowledge is limited, whereas mutual learning could help them save time and tackle some difficulties. SPM4

However, as we went on analyzing the data and looking for deeper and less intuitive insights, we found that the evidence of this open cultural approach supporting a firm-wide transfer of 
knowledge across projects was counterbalanced by other, contradictory information that suggested the existence of knowledge-hoarding attitudes. In particular, based on personal relationships and preferences, project team members were part of informal groups and subgroups that spanned across projects. And as we probed into our informants' perceptions about the differences between friends and "close colleagues" on one side and other "more generic colleagues" on the other side, we learned that it was a common belief that "knowledge can be hoarded completely or partially from those you are not familiar with”. Also, many project members claimed individual "ownership” of some special technical knowledge, and believed that hoarding such knowledge was justified and widely accepted. Interestingly, such attitude of "keeping knowledge for yourself" was particularly strong in more experienced project managers who acted as mentors to younger colleagues and apprentices. In fact, there was a shared belief among senior mentors that "sharing too much of your knowledge will make you useless”, and eventually redundant. Such selective approach to knowledge transfer was expressed by interviewees in statements such as:

It depends on personal relationships... If there isn't a good personal relationship, they are reluctant to share knowledge completely, and they might partially hoard knowledge to normal colleagues and unfamiliar people. SPM5

As there is no protection of intellectual property on some technical knowledge in the firm, project members hoard the special technical knowledge... they are reluctant to share it with others. SPM8

In terms of special construction techniques, people don't like to be imitated by others. PD1

Traditionally, as mentors, we believe that sharing too much knowledge and experience to apprentices will put ourselves out of work. SPM3

Another shared belief affecting the transfer of knowledge from project to project concerned the negative attitude to work and collaboration displayed by some construction workers. For example, senior project managers concurred that "construction workers with a low level of literacy are money-oriented and do not follow their mentors’ approaches; they are resistant to change and tend not to look for and reuse new knowledge.” For this category of workers, 
"reusing knowledge often means changing or expanding the project requirements. Therefore, some construction workers even ask for a salary increase because the requirements have changed.” Other interviewees explained that the same money-oriented workers "even regard the Enterprise Information Platform as useless.”

With respect to the evaluation of formal and informal knowledge transfer mechanisms, project managers suggested that informal interactions were complementary to formal mechanisms such as meetings, seminars and presentations. But while formal initiatives had wide coverage of people and projects, and often supported the transfer of knowledge characterized by high levels of complexity, informal interactions only took place within small groups, and the knowledge exchanged through informal interactions "kind of lacks validity and legitimacy”. Specifically, there was a shared belief that formal knowledge transfer mechanisms represented the formal authority:

When senior managers attend meetings, inspections, seminars and presentations, we must pay close attention to what is said in those settings, as they represent the formal authority of the organization. SPM1

The validity and feasibility of knowledge exchanged informally... remain unknown... However, the knowledge transferred in formal occasions is valid, legitimate and feasible. It can be used immediately and it is applicable to our projects. The knowledge transferred in formal meetings is acknowledged by all colleagues. PM6

However, since the information transferred through formal mechanisms was rather concise and not supported by extensive illustrations, informal interactions enabled project managers to gain a deeper understanding of some specific pieces of knowledge, and exchange information on a greater number of topics not necessarily covered by formal mechanisms (for example, knowledge about cost control and management). Good personal relationships facilitated mutual learning in informal interactions. Therefore, there was the shared belief among project managers that knowledge could be shared completely only between project managers who knew each other, and that informal interactions with friends could help exchange more types 
of knowledge and attain a deeper understanding of each of them. This belief was expressed in statements such as:

My colleagues [other project managers] are willing to share knowledge completely with those they are familiar and have emotional ties with. SPM5

The knowledge could be exchanged more deeply through informal interactions with friends. With a good personal relationship, we are willing to exchange more types of knowledge completely... SPM2

We only share special construction techniques and methods and knowledge about cost control and management with those we are familiar with. SPM3

Further evidence of the multifaceted influence of organizational culture on knowledge management and transfer practices was somewhat related to the preference for formal mechanisms of transfer. Such evidence showed that project managers were willing to obey to organizational rules and follow company's policies for project execution and delivery. The underlying shared belief was that company's rules and policies on safety and quality control and management had to be followed strictly and closely. In this respect, beliefs and artifacts went hand in hand. In fact, as quarterly inspections focused specifically on performance indicators for safety and quality control, project managers were punished and fined when their projects did not reach the required standards. Punishments in the quarterly inspection were regarded as "shameful”, and "are to be avoided by all means”. To achieve the desired standards and preserve themselves from punishment, project managers, who "represented the formal authority within projects”, encouraged project teams to accept and circulate as much as possible knowledge about safety and quality control and management.

Project performance and salaries and bonus are linked. We must follow the company's rules and policies on safety and quality control and management. Those responsible for projects where the performance of safety and quality control and management do not reach the standards will be punished and fined in quarterly inspections. PD2

Project managers believe it's like losing face if they are punished in the quarterly inspection. PM3 
At the same time, other elements of the organizational culture prevented people from transferring other types of knowledge across projects. For example, it was a common belief that taking the initiative to share knowledge "can be seen as showing off, or an opportunity taken to criticize the project management style or approach of others”. Project managers also believed that "people should not intervene in colleagues' actions unless you are asked for suggestions”. In the words of our informants:

Taking initiative to share knowledge to people who you don't know will be regarded as 'show-off', because it's like criticizing their work, or highlighting their lack of competence in the execution of the project. SPM8

I won't take initiative to share what I know because it will be regarded as ostentatious. Project managers won't share their knowledge unless they are asked. SPM4

I won't say anything unless I'm asked for help and suggestions. I don't like to intervene in others' businesses. PD2

\section{DISCUSSION}

Our understanding of the influence that organizational culture and subcultures have on knowledge management and transfer in project-based settings is still limited (Alavi, Kayworth, \& Leidner, 2005; Eskerod \& Skriver, 2007; Fong, 2008; Fong \& Kwok, 2009; Tseng, 2010; Wiewiora et al., 2013; Yih - Tong Sun \& John, 2005). The intricate interrelationships between the various elements of an organization's culture make cultural issues in projects extremely complex, and difficult to study (Ajmal et al., 2009; Ajmal \& Koskinen, 2008). To tackle such complexity, we started to disentangle those interrelationships by teasing out separately the fundamental elements of Builc’s organizational culture (artifacts, norms, and shared beliefs), and gaining insights into how each of them influenced the transfer of knowledge across projects.

Our findings extend early work on professional cultures (Ajmal et al., 2009; Ajmal \& Koskinen, 2008) and subcultures (De Long \& Fahey, 2000) by identifying some of the mechanisms by which corporate-level organizational cultures superimpose a strong and 
pervasive layer of cultural elements on lower organizational levels, such as subsidiaries and projects. In the experience of our case study firm, projects included several professional cultures and subcultures (Ajmal et al., 2009; Ajmal \& Koskinen, 2008). However, some core values and beliefs characterizing the culture of the parent company were widely shared and nurtured by project members (Mueller, 2015). And such superimposed cultural elements played a crucial role in suggesting which types of knowledge it was most important to share, transfer and leverage, even when the local subcultures or professional cultures had set different transfer priorities. This phenomenon became particularly evident to us when we compared the different attitudes of project employees towards the transfer of two distinct types of knowledge. On the one hand, project-level subcultures and professional cultures supported the belief that it was key to transfer and share as much as possible knowledge about construction techniques and methods, as well as innovative project management approaches and practices. Project managers were regarded as preferential "channels" for conveying this types of knowledge, and such belief was reinforced by a range of artifacts including learning materials, internal reports, case studies, and written announcements. On the other hand, the organizational culture of the parent company led project managers and employees to treat knowledge about safety and quality control and management as the top priority for any transfer initiatives, and the beliefs about the importance of meeting safety and quality standards were constantly reinforced by artifacts such as quarterly inspections, punishments and rewards. Moreover, the improved performance (in terms of decreasing number of project problems, pitfalls, reworks, costs and waste) demonstrated that the transfer across projects of knowledge about safety and quality was successful. This is in partial contradiction with extant research positing that a culture that tolerates project mistakes is crucial for effective knowledge transfer (Hanisch, Lindner, Mueller, \& Wald, 2009; Lindner \& Wald, 2011). 
Our study also advances extant research on the legitimacy of knowledge (De Long \& Fahey, 2000) by suggesting that the organizational culture may legitimate knowledge that is closely tied to the formal authority of the firm, and eventually influence people’s preference as to which knowledge transfer mechanisms are to be enacted. We found a strong preference of project managers for formal knowledge transfer mechanisms and initiatives that emanated from the formal authority of the firm, and entailed intensive exercises of knowledge codification (Boh, 2007; Fong \& Kwok, 2009) into artifacts such as quarterly seminars, presentations and learning materials. Project managers believed that the knowledge transferred through formal mechanisms had greater legitimacy, feasibility and validity. And these shared beliefs about knowledge legitimacy seemed to be reinforced not only by the corporate culture but also by the national culture. We know that the Chinese national culture is characterized by a high level of power distance, and that employees of Chinese organizations usually accept the role of formal authority (Hofstede, 2010), and tend to believe that the rules set by senior management must be followed with obedience and diligence. Indeed, project managers at Builc felt strongly influenced by the presence of senior management in meetings and gatherings, because they represented the formal authority of the firm. Special attention was paid to all instructions coming from senior management, and to the knowledge transferred by them through formal mechanisms. In fact, the transfer of knowledge across projects relied primarily on formal mechanisms. This is a counterintuitive finding, because previous studies have showed that knowledge transfer in PBOs largely depend on direct and informal interactions between colleagues, social ties of project teams, and interpersonal and social aspects (Almeida \& Soares, 2014; Almeida \& Phene, 2004; Bartsch et al., 2013; Bresnen, Edelman, Newell, Scarbrough, \& Swan, 2003; Newell, Bresnen, Edelman, Scarbrough, \& Swan, 2006).

Furthermore, our empirical evidence suggests that organizational culture can play a farreaching role in determining not only what knowledge can be transferred but also (1) the 
conditions under which either sharing or hoarding are to be preferred, and (2) the extent to which it is acceptable to share or hoard one's knowledge. The belief that knowledge could be shared completely only with individuals regarded as familiar was deeply rooted in Builc's organizational culture, but also supported by aspects of the national culture. Previous research has showed that China has a relatively low level of individualism. Employees in Chinese organizations perform best when they work towards group goals, and the relationships between colleagues tend to be more cooperative within groups (Hofstede, 2010). In the experience of Builc, informal groups were formed across project boundaries on the basis of good personal relationships, which made project managers more inclined to share their knowledge unreservedly. For example, much of the knowledge about cost control and management was exchanged mainly within informal groups, and only occasionally through formal mechanisms. By contrast, project managers were more likely to hoard their knowledge completely, or share it only to a limited extent, with colleagues who were not part of those groups. In this respect, a striking piece of evidence was that such knowledge-hoarding behavior was particularly recurrent when special and innovative technical insights were most needed in strategic projects. These projects were often characterized by fierce competition between project members, due to the widely shared belief that special technical knowledge should be almost subject to individual ownership rights and, in absence of alternative mechanisms of protection of intellectual property, it was acceptable to hoard it. As this shared belief supported and exacerbated competitive dynamics between project members, the cooperative relationships that usually enable and facilitate knowledge transfer (Daniilidis, Lamperstorfer, Kirschner, Kain, \& Lindemann, 2010; Goh, 2002) were compromised. This evidence provides further support to extant research on the role of organizational culture in condoning knowledge-hoarding behaviors and supporting individuals' sense of ownership of their knowledge (De Long \& Fahey, 2000). 
Finally, our study sheds light on another way in which organizational culture may hamper the transfer of knowledge across projects. Although issues of knowledge hoarding have often been found in projects (e.g. Issa \& Haddad, 2008), our study shows that organizational culture may confer on experienced mentors a unique position of authority, and support their conduct in terms of selecting and filtering the knowledge that is shared and leveraged. This is a relatively counterintuitive finding for a setting such as the Chinese construction industry, where the labor-intensive organization of construction activities relies heavily on the experience of expert mentors. Good mentoring and apprenticeship have traditionally been perceived as pervasive norms, especially when the firm cannot provide all project members with adequate technical training. Indeed, mentors usually are the primary source of valuable knowledge and experience, and play a fundamental role in the attainment of satisfactory project performance. However, in our case study firm, the norm of mentoring and apprenticeship as important channels for knowledge transfer was often suspended, and mentors did not share their knowledge and experience with apprentices completely. Such selective approach was supported by the mentors' shared belief that sharing too much of what they knew would make them "useless as project experts", and put their job at risk (Ajmal et al., 2009; Ajmal \& Koskinen, 2008). To prevent themselves from prospective redundancy, mentors partly hoarded knowledge and deliberately hindered the transfer process. But because of their unique role and position, such behavior was regarded as acceptable by the firm's organizational culture, and hence tolerated. Overall, then, the norm of mentoring and apprenticeship was found to exert both positive and negative influence upon knowledge transfer. 


\section{References}

Ajmal, M. M. \& Koskinen, K. U. 2008. Knowledge transfer in project-based organizations: An organizational culture perspective. Project Management Journal, 39(1): 7-15.

Ajmal, M. M., Kekale, T., \& Koskinen, K. U. 2009. Role of organisational culture for knowledge sharing in project environments. International Journal of Project Organisation and Management, 1(4): 358-374.

Alavi, M., Kayworth, T. R., \& Leidner, D. E. 2005. An Empirical Examination of the Influence of Organizational Culture on Knowledge Management Practices. Journal of Management Information Systems, 22(3): 191-224.

Allen, T. J. 1984. Managing the Flow of Technology: Technology Transfer and the Dissemination of Technological Information Within the R\&D Organization: MIT Press.

Almeida, M. V. \& Soares, A. L. 2014. Knowledge sharing in project-based organizations: Overcoming the informational limbo. International Journal of Information Management, 34(6): 770-779.

Almeida, P. \& Phene, A. 2004. Subsidiaries and knowledge creation: the influence of the MNC and host country on innovation. Strategic Management Journal, 25(8-9): 847-864.

Alvesson, M. \& Kärreman, D. 2001. Odd couple: making sense of the curious concept of knowledge management. Journal of management studies, 38(7): 995-1018.

Alvesson, M. 2012. Understanding Organizational Culture: SAGE Publications.

Argote, L. 1999. Organizational Learning: Creating, Retaining and Transferring Knowledge: Springer.

Argote, L. \& Ingram, P. 2000. Knowledge Transfer: A Basis for Competitive Advantage in Firms. Organizational Behavior and Human Decision Processes, 82(1): 150-169.

Argote, L., McEvily, B., \& Reagans, R. 2003. Managing Knowledge in Organizations: An Integrative Framework and Review of Emerging Themes. Management Science, 49(4): 571-582.

Argote, L. \& Miron-Spektor, E. 2011. Organizational Learning: From Experience to Knowledge. Organization Science, 22(5): 1123-1137.

Argote, L. 2012. Organizational Learning: Creating, Retaining and Transferring Knowledge: Springer.

Aubrey, R. \& Cohen, P. M. 1995. Working wisdom: timeless skills and vanguard strategies for learning organizations: Jossey-Bass Publishers.

Barney, J. B. 1986. Organizational Culture: Can It Be a Source of Sustained Competitive Advantage? Academy of Management Review, 11(3): 656-665.

Barriball, L. K. \& While, A. 1994. Collecting data using a semi-structured interview: a discussion paper. Journal of Advanced Nursing, 19(2): 328-335.

Bartsch, V., Ebers, M., \& Maurer, I. 2013. Learning in project-based organizations: The role of project teams' social capital for overcoming barriers to learning. International Journal of Project Management, 31(2): 239-251.

Biernacki, P. \& Waldorf, D. 1981. Snowball Sampling: Problems and Techniques of Chain Referral Sampling. Sociological Methods \& Research, 10(2): 141-163. 
Boh, W. F. 2007. Mechanisms for sharing knowledge in project-based organizations. Information and Organization, 17(1): 27-58.

Brady, T. \& Davies, A. 2004. Building Project Capabilities: From Exploratory to Exploitative Learning. Organization Studies, 25(9): 1601-1621.

Bresnen, M., Edelman, L., Newell, S., Scarbrough, H., \& Swan, J. 2003. Social practices and the management of knowledge in project environments. International Journal of Project Management, 21(3): 157-166.

Cameron, K. S. \& Quinn, R. E. 2005. Diagnosing and Changing Organizational Culture: Based on the Competing Values Framework: Wiley.

Cattani, G., Täube, F. A., Ferriani, S., Frederiksen, L., \& Silverman, B. 2011. Project-Based Organizing and Strategic Management: Emerald.

Collins, H. 2004. Interactional expertise as a third kind of knowledge. Phenomenology and the Cognitive Sciences, 3(2): 125-143.

Collins, H. \& Evans, R. 2008. Rethinking Expertise: University of Chicago Press.

Corbin, J. \& Strauss, A. 2014. Basics of Qualitative Research: Techniques and Procedures for Developing Grounded Theory: SAGE Publications.

Cummings, T. \& Worley, C. 2014. Organization Development and Change: Cengage Learning.

Daniilidis, C., Lamperstorfer, T., Kirschner, R., Kain, A., \& Lindemann, U. 2010. A systematic approach to design a knowledge transfer framework for process improvement projects, Industrial Engineering and Engineering Management: 183-187.

Davenport, T. H., Jarvenpaa, S. L., \& Beers, M. C. 1996. Improving knowledge work processes. MIT Sloan Management Review, 37(4): 53.

De Long, D. W. \& Fahey, L. 2000. Diagnosing cultural barriers to knowledge management. Academy of Management Executive, 14(4): 113-127.

DeFillippi, R. J. \& Arthur, M. B. 1998. Paradox in project-based enterprise: the case of film making. California management review, 40(2): 125-139.

Eisenhardt, K. M. 1989. Building Theories from Case Study Research. The Academy of Management Review, 14(4): 532-550.

Eskerod, P. \& Skriver, H. J. 2007. Organizational culture restraining in-house knowledge transfer between project managers - A case study. Project Management Journal, 38(1): 110-122.

Evans, J. M., Hendron, M. G., \& Oldroyd, J. B. 2015. Withholding the Ace: The Individualand Unit-Level Performance Effects of Self-Reported and Perceived Knowledge Hoarding. Organization Science, 26(2): 494-510.

Fiol, C. M. \& Lyles, M. A. 1985. Organizational Learning. Academy of Management Review, 10(4): 803-813.

Fong, P. S. W. 2008. Can we learn from our past? Managing knowledge within and across projects. In I. Becerra-Fernandez \& D. Leidner (Eds.), Knowledge management: An evolutionary view, vol. 12: 204-226. Armonk, New York: ME Sharpe Inc. 
Fong, P. S. W. \& Kwok, C. W. C. 2009. Organizational Culture and Knowledge Management Success at Project and Organizational Levels in Contracting Firms. Journal of Construction Engineering and Management, 135(12): 1348-1356.

Fraser, S., Greene, F. J., \& Mole, K. F. 2007. Sources of Bias in the Recall of Self-Generated Data: The Role of Anchoring. British Journal of Management, 18(2): 192-208.

Gann, D. M. \& Salter, A. J. 2000. Innovation in project-based, service-enhanced firms: the construction of complex products and systems. Research policy, 29(7): 955-972.

Given, L. M. 2008. The SAGE Encyclopedia of Qualitative Research Methods: SAGE Publications.

Glaser, B. G. \& Strauss, A. L. 1967. The Discovery of Grounded Theory: Strategies for Qualitative Research. Chicago: Aldine de Gruyter.

Goh, S. C. 2002. Managing effective knowledge transfer: an integrative framework and some practice implications. Journal of Knowledge Management, 6(1): 23-30.

Grant, R. M. 1996. Toward a knowledge-based theory of the firm. Strategic Management Journal, 17: 109-122.

Hall, J. \& Sapsed, J. 2005. Influences of knowledge sharing and hoarding in project-based firms. In P. Love, Z. Irani, \& P. Fong (Eds.), Management of Knowledge in Project Environments: 57-79. Oxford: Butterworth-Heinemann.

Handy, C. 2007. Understanding Organizations: Penguin Books Limited.

Hanisch, B., Lindner, F., Mueller, A., \& Wald, A. 2009. Knowledge management in project environments. Journal of Knowledge Management, 13(4): 148-160.

Heusinkveld, S. 2009. Reflections on a reflective cycle: Building legitimacy in design knowledge development. Organization Studies.

Hobday, M. 2000. The project-based organisation: an ideal form for managing complex products and systems? Research Policy, 29(7/8): 871.

Hofstede, G., Neuijen, B., Ohayv, D. D., \& Sanders, G. 1990. Measuring Organizational Cultures: A Qualitative and Quantitative Study Across Twenty Cases. Administrative Science Quarterly, 35(2): 286-316.

Hofstede, G. 2010. Cultures and Organizations: Software of the Mind. London: McGrawHill.

Hsu, I. \& Sabherwal, R. 2012. Relationship between intellectual capital and knowledge management: an empirical investigation. Decision Sciences, 43(3): 489-524.

Hudson, B. A. \& Wong-MingJi, D. J. 2001. Legitimacy and Illegitimacy: A Contest of Institutional Knowledge as Power. Organization, 8(2): 396-402.

Issa, R. A. \& Haddad, J. 2008. Perceptions of the impacts of organizational culture and information technology on knowledge sharing in construction. Construction Innovation, 8(3): 182-201.

Janz, B. D. \& Prasarnphanich, P. 2003. Understanding the antecedents of effective knowledge management: The importance of a knowledge-centered culture. Decision sciences, 34(2): 351-384. 
Kamara, J., Anumba, C., \& Carrillo, P. M. 2008. Cross-Project Knowledge Management. In C. J., C. E. Anumba, \& P. M. Carrillo (Eds.), Knowledge Management in Construction. Oxford: Blackwell Publishing.

Kane, A. A., Argote, L., \& Levine, J. M. 2005. Knowledge transfer between groups via personnel rotation: Effects of social identity and knowledge quality. Organizational Behavior and Human Decision Processes, 96(1): 56-71.

Karlsen, J. T. \& Gottschalk, P. 2004. Factors Affecting Knowledge Transfer in IT Projects. Engineering Management Journal, 16(1): 3-11.

Keegan, A. \& Turner, J. R. 2002. The management of innovation in project-based firms. Long range planning, 35(4): 367-388.

Kogut, B. \& Zander, U. 1992. Knowledge of the Firm, Combinative Capabilities, and the Replication of Technology. Organization Science, 3(3): 383-397.

Landaeta, R. E. 2008. Evaluating Benefits and Challenges of Knowledge Transfer Across Projects. Engineering Management Journal, 20(1): 29-38.

Lee, S., Gon Kim, B., \& Kim, H. 2012. An integrated view of knowledge management for performance. Journal of Knowledge Management, 16(2): 183-203.

Leidner, D. \& Kayworth, T. 2006. Review: a review of culture in information systems research: toward a theory of information technology culture conflict. MIS Q., 30(2): 357-399.

Lincoln, Y. S. \& Guba, E. G. 1985. Naturalistic Inquiry: SAGE Publications.

Lindner, F. \& Wald, A. 2011. Success factors of knowledge management in temporary organizations. International Journal of Project Management, 29(7): 877-888.

Lundin, R. A. \& Söderholm, A. 1995. A theory of the temporary organization. Scandinavian Journal of Management, 11(4): 437-455.

McDermott, R. 1999. Why Information Technology Inspired But Cannot Deliver Knowledge Management. California Management Review, 41(4): 103-117.

McDermott, R. \& O’Dell, C. 2001. Overcoming cultural barriers to sharing knowledge. Journal of Knowledge Management, 5(1): 76-85.

Miles, M. B. \& Huberman, A. M. 1994. Qualitative Data Analysis: An Expanded Sourcebook: SAGE Publications.

Mueller, J. 2015. Formal and Informal Practices of Knowledge Sharing Between Project Teams and Enacted Cultural Characteristics. Project Management Journal, 46(1): 53-68.

Newell, S., Bresnen, M., Edelman, L., Scarbrough, H., \& Swan, J. 2006. Sharing Knowledge Across Projects: Limits to ICT-led Project Review Practices. Management Learning, 37(2): 167-185.

Pemsel, S. \& Müller, R. 2012. The governance of knowledge in project-based organizations. International Journal of Project Management, 30(8): 865-876.

Pemsel, S. \& Wiewiora, A. 2013. Project management office a knowledge broker in projectbased organisations. International Journal of Project Management, 31(1): 31-42.

Rai, R. K. 2011. Knowledge management and organizational culture: a theoretical integrative framework. Journal of Knowledge Management, 15(5): 779-801. 
Ralston, D. A., Terpstra-Tong, J., Terpstra, R. H., Wang, X., \& Egri, C. 2006. Today's stateowned enterprises of China: are they dying dinosaurs or dynamic dynamos? Strategic Management Journal, 27(9): 825-843.

Ray, D. 2014. Overcoming cross-cultural barriers to knowledge management using social media. Journal of Enterprise Information Management, 27(1): 45-55.

Rivera-Vazquez, J. C., Ortiz-Fournier, L. V., \& Flores, F. R. 2009. Overcoming cultural barriers for innovation and knowledge sharing. Journal of Knowledge Management, 13(5): 257-270.

Sackmann, S. A. 1992. Culture and Subcultures: An Analysis of Organizational Knowledge. Administrative Science Quarterly, 37(1): 140-161.

Schein, E. H. 1990. Organizational Culture. American Psychologist, 45(2): 109-119.

Schein, E. H. 2010. Organizational Culture and Leadership: John Wiley \& Sons.

Sense, A. J. 2004. An architecture for learning in projects? Journal of Workplace Learning, 16(3): 123-145.

Sense, A. J. 2007. Structuring the project environment for learning. International Journal of Project Management, 25(4): 405-412.

Shao, Z., Feng, Y., \& Liu, L. 2012. The mediating effect of organizational culture and knowledge sharing on transformational leadership and Enterprise Resource Planning systems success: An empirical study in China. Computers in Human Behavior, 28(6): 2400-2413.

Simonin, B. L. 2004. An empirical investigation of the process of knowledge transfer in international strategic alliances. Journal of international business studies, 35(5): 407-427.

Spender, J. C. 1996. Making knowledge the basis of a dynamic theory of the firm. Strategic Management Journal, 17: 45-62.

Spender, J. C. \& Grant, R. M. 1996. Knowledge and the Firm: Overview. Strategic Management Journal, 17: 5-9.

Stokes, P., Baker, C., \& Lichy, J. 2016. The Role of Embedded Individual Values, Belief and Attitudes and Spiritual Capital in Shaping Everyday Postsecular Organizational Culture. European Management Review, 13(1): 37-51.

Szulanski, G. 1996. Exploring Internal Stickiness: Impediments to the Transfer of Best Practice Within the Firm. Strategic Management Journal, 17: 27-43.

Tseng, S. M. 2010. The correlation between organizational culture and knowledge conversion on corporate performance. Journal of Knowledge Management, 14(2): 269-284.

Tushman, M. L. 1977. Special boundary roles in the innovation process. Administrative science quarterly: 587-605.

Wang, D., Su, Z., \& Yang, D. 2011. Organizational culture and knowledge creation capability. Journal of Knowledge Management, 15(3): 363-373.

Whitley, R. 2006. Project-based firms: new organizational form or variations on a theme? Industrial and Corporate Change, 15(1): 77-99. 
Wiewiora, A., Trigunarsyah, B., Murphy, G., \& Coffey, V. 2013. Organizational culture and willingness to share knowledge: A competing values perspective in Australian context. International Journal of Project Management, 31(8): 1163-1174.

Wilkins, A. L. \& Ouchi, W. G. 1983. Efficient Cultures: Exploring the Relationship Between Culture and Organizational Performance. Administrative Science Quarterly, 28(3): 468481.

Yih-Tong Sun, P. \& John, L. S. 2005. An investigation of barriers to knowledge transfer. Journal of Knowledge Management, 9(2): 75-90.

Yin, R. K. 2013. Case Study Research: Design and Methods (5th ed.): SAGE Publications.

Zander, U. \& Kogut, B. 1995. Knowledge and the Speed of the Transfer and Imitation of Organizational Capabilities: An Empirical Test. Organization Science, 6(1): 76-92.

Zheng, W., Yang, B., \& McLean, G. N. 2010. Linking organizational culture, structure, strategy, and organizational effectiveness: Mediating role of knowledge management. Journal of Business Research, 63(7): 763-771. 